\title{
Pressure Fluctuations in Jet Spouted Beds
}

\author{
Lii-ping Leu* and Rong-Shyan Pan
}

\author{
Department of Chemical Engineering, National Taiwan University, Taipei 106-17, Taiwan
}

$\mathrm{T}$ he classical spouted bed (CSB) is widely used in gas-solid contact operations, such as drying, granulation and coating (Mathur and Gishler, 1955). A jet spouted bed (JSB) is the new regime with hydrodynamic differences from the classical spouted bed in the conical contactors (Olazar et al., 1992). It was first proposed by Markowski and Kaminski (1983) for high particle movement, high turbulence, low gas residence time and high particle interaction. They described the characteristics of the jet spouted bed as high velocity; high bed voidage, over 0.75; cyclic movement of the particles; and hydrodynamic behaviour different from that of CSB. The hydrodynamic differences from the CSB in the conical contactors are: (1) hysteresis is nonexistence in pressure drop vs. velocity curves; (2) there are fewer instability problems; (3) the experimental results of minimum jet spouting do not follow the correlations applicable to spouted beds. So the performance of these two types of reactors is quite different. JSB is characterized by high particle movement resulting from the very high gas spouting velocity and higher bed voidage. It has been used for drying suspensions, solutions and pasty materials due to vigorous solids motion and intimate gas-solids contact. San Jose et al. (1992) found the expansion of the spouted bed in a conical contactor leads to the jet spouted bed regime, for which the gas-solid contact is very vigorous and cyclic movement of the particles characteristic of the spouted beds is attained. They proposed a hydrodynamic correlation for the calculation of the minimum jet spouting velocity that is different from the conventional spouted bed. They also proposed a correlation for the calculation of voidage in the expansion of conical spouted beds. Olazar et al. (1992) discussed the stable operation conditions for gas-solid contact regimes in conical spouted beds. They also delimited the design parameters for the stable operation of jet spouted beds. They described after the stable regime of spouting in increasing the superficial gas velocity, both annular and spout zones characteristic of classic spouting become progressively confused and they termed it as the transition zone. In the CSB, the particles are circulated through the spout and annular zones. As the superficial gas velocity increases until the spout and annular zones are no longer differentiated and the bed voidage is uniform, a new situation corresponding to incipient jet spouting is reached. When this is reached, it stays stable at higher velocity with a constant value of pressure drop in a velocity range. Leu and Teng (2000) studied the heat transfer in jet spouted beds by using a heat flux meter (Chen and Chen, 1992) and found that the wall-to-bed heat transfer coefficient in the jet spouted bed region is almost constant and the value is in the range of $200 \sim 500 \mathrm{~W} / \mathrm{m}^{2} \cdot \mathrm{K}$.

In this study, the effect of particle size, shape of particles and static bed height on the regime transition has been characterized from the pressure fluctuation signal, the minimum jet spouted velocity was determined from the measurement of standard deviation of pressure fluctuations. This information is required for proper design, scale up and operation of jet spouted beds.

*Author whom correspondence may be addressed: E-mail address: lleulii@ntu.edu.tw
Jet spouted beds that consisted of a transparent Plexiglas cylindrical column of $1 \mathrm{~m}$ high and a conical base with cone angles of $30^{\circ}, 36^{\circ}$, and $40^{\circ}$ were used in this study. The particles used were spherical glass beads with an average diameter of 1.7, 2.1 and $3 \mathrm{~mm}$, respectively, and particle size of $2.2-3.1 \mathrm{~mm}$, nonspherical rice particles. The effect of size and shape of particles, and static bed height on the minimum jet spouting velocity, and standard deviation of pressure fluctuations, was investigated. The results show that the minimum jet spouting velocity and pressure drop increased as the bed height and particle size increased. The minimum jet spouting velocity could be determined from the plot of standard deviation of pressure fluctuations vs. superficial gas velocity. The results obtained were in close agreement with the results of other methods in the literature.

On a utilisé dans cette étude des lits jaillissants à jets composés d'une colonne cylindrique en Plexiglas transparente de $1 \mathrm{~m}$ de haut et $\mathrm{d}^{\prime}$ une base conique ayant des angles de $300,36^{\circ}$ et $40^{\circ}$. Les particules utilisées sont des billes de verre sphériques de 1,7 $\mathrm{mm}, 2,1 \mathrm{~mm}$ et $3 \mathrm{~mm}$ de diamètre moyen, respectivement, et des particules de riz non sphériques de 2,2$3,1 \mathrm{~mm}$ de diamètre moyen. L'effet de la taille et de la forme des particules, de la hauteur de lit statique sur la vitesse de jaillissement des jets minimale, et l'écart type des fluctuations de pression, a été étudié. Les résultats montrent que la vitesse de jaillissement des jets minimale et la perte de charge augmentent avec la hauteur du lit et la taille des particules. La vitesse de jaillissement des jets minimale peut être déterminée à partir du tracé de l'écart type des fluctuations de pression par rapport à la vitesse de gaz superficielle. Les résultats obtenus montrent un bon accord avec les résultats obtenus par d'autres méthodes et décrits dans la littérature scientifique.

Keywords: jet spouted bed, conical spouted bed, minimum jet spouting velocity, pressure fluctuations.

entrained by a co-current flow of gas (fountain), and a dense phase annular region (annulus) with countercurrent percolation of gas as described by Mathur and Epstein (1974) for the classical spouted bed. In region $A B$, the particles near the entrance region of gas inlet moved but the whole bed was at the fixed bed - not in the spouted state. The S.D. varies only slightly with the 
increase of gas velocity. After point B was reached, the whole bed was in the state of spouting. With the increase of gas velocity, the S.D. was increased due to the strong movement of the particles in the bed. Point $C$ was the maximum pressure fluctuation point. It was the boundary of spouted bed and transition region. After point $C$, the whole bed was in the state of transition zone. The particles in the annular zone transferred to spouting zone and the bed height started to decrease. The particles near the bed bottom diminished slowly. The pressure drop decreased with the increase of the superficial gas velocity. The particles in the annular region were transferred to the fountain. The three different regions in CSB were no longer easy to distinguish. After the superficial gas velocity reached the point $D$, the whole bed became uniform. The particles had good circulation in the bed and less dead region at the bottom of the bed. It was the dilute gas-solid system where the boundaries between zones were no longer distinct as in the CSB, and the bed voidage was uniform for the whole bed. It was the onset of jet spouting as described by Makowski and Kaminski (1983) and Olazar et al. (1992). At this state, the pressure fluctuations were very small and the pressure drop was constant. The S.D. value was kept as a constant. The minimum jet spouting velocity could thus be determined.

Figure 3 shows the typical pressure-time curves as obtained by the measurement of pressure drop. From these curves, the hydrodynamics of spouted bed could be obtained. In Figure $3(a)$, the bed was in the spouted bed region, the amplitude of pressure fluctuations was strong, and the fluctuations were periodic and regular. The particles in the bed moved regularly through the spout, fountain and annulus regions. In Figure 3 (b) the bed was in the transition state. The fluctuations were different from the state in spouting, there were fluctuations but the periodicity disappeared. It was clear that the bed was in a different state. In Figure 3(c), where the bed was on jet spouting, the pressure fluctuations were small and nearly uniform due to the uniformity of the bed as shown in Figure 2 . From these figures, the S.D. became smaller as the superficial gas velocity increased; the shape of the waveform was also different. It was clear the spouted bed, transition region, and jet spouted bed were three different flow regimes.

\section{Effect of Particle Size and Static Bed Height on Minimum Jet Spouting Velocity}

The result of the effect of particle size and static bed height on minimum jet spouting velocity was similar as described by Olazar et al. (1992). $U_{m j}$ increased with the increase of the static bed height if the angle of the conical base and particle size were kept constant. If the angle of the conical base and static bed height were kept constant, $U_{m j}$ increased with the increase of

\begin{tabular}{|l|l|l|l|l|}
\hline$\gamma($ degree $)$ & $D_{c}(\mathrm{~mm})$ & $D_{i}(\mathrm{~mm})$ & $D_{o}(\mathrm{~mm})$ & $H_{c}(\mathrm{~mm})$ \\
\hline 30 & 164 & 30 & 15 & 244.8 \\
\hline 36 & 190 & 25 & 15 & 252.4 \\
\hline 40 & 240 & 25 & 15 & 240 \\
\hline
\end{tabular}

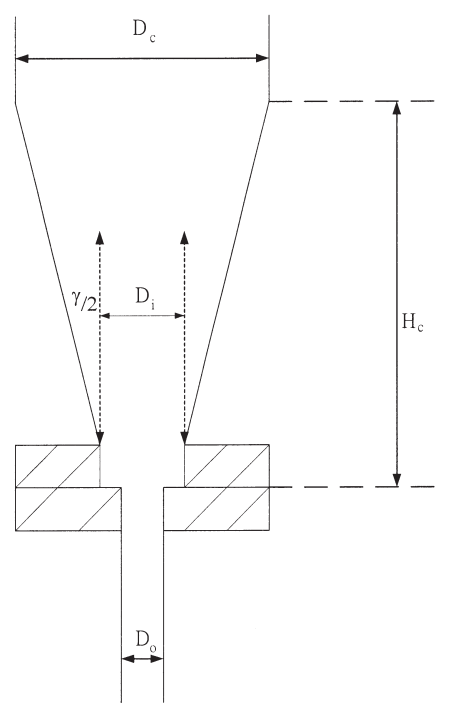

Figure 1. Geometric factors of the bed.

the particle size. The reason was due to the increase of the bed weight. It was similar to the minimum spouting velocity, which is a function of bed depth (Mathur and Epstein, 1974).

\section{Effect of Shape of Particles on Minimum Jet Spouting Velocity}

The effect of irregular shape particle was shown in Figure 4. Whether the shape of particles was spherical (Figure 2) or in other shape, the S.D. method could be used to find the minimum jet spouting velocity. In the same figure, the S.D. method was compared with the traditional pressure drop method, they were in good agreement.

The minimum jet spouting velocity obtained from S.D. method here could be correlated well by the Olazar's correlation equation (1992) with slightly different value of a coefficient.

$\left(R e_{o}\right)_{m j}=5.926 A r^{0.35}\left(D_{b} / D_{o}\right)^{1.46}(\tan \gamma / 2)^{-0.53}$

Table 1. Physical properties of particles used.

\begin{tabular}{lcccc}
\hline & diameter $d_{p}(\mathrm{~mm})$ & density $\rho_{s}(\mathrm{~kg} / \mathrm{m} 3)$ & shape & shape factor \\
\hline glass bead G1 & 1.7 & 2420 & spherical & 1.0 \\
glass bead G2 & 2.1 & 2420 & spherical & 1.0 \\
glass bead G3 & 3.0 & 2420 & spherical & 1.0 \\
rice R1 & 3.1 & 1440 & non-spherical & $0.87^{*}$ \\
rice R2 & 2.2 & 1330 & non-spherical & $0.8^{*}$ \\
rice R3 & 2.5 & 1350 & non-spherical & $0.75^{*}$ \\
\hline
\end{tabular}

${ }^{*}$ Rough prediction by geometric considerations. 


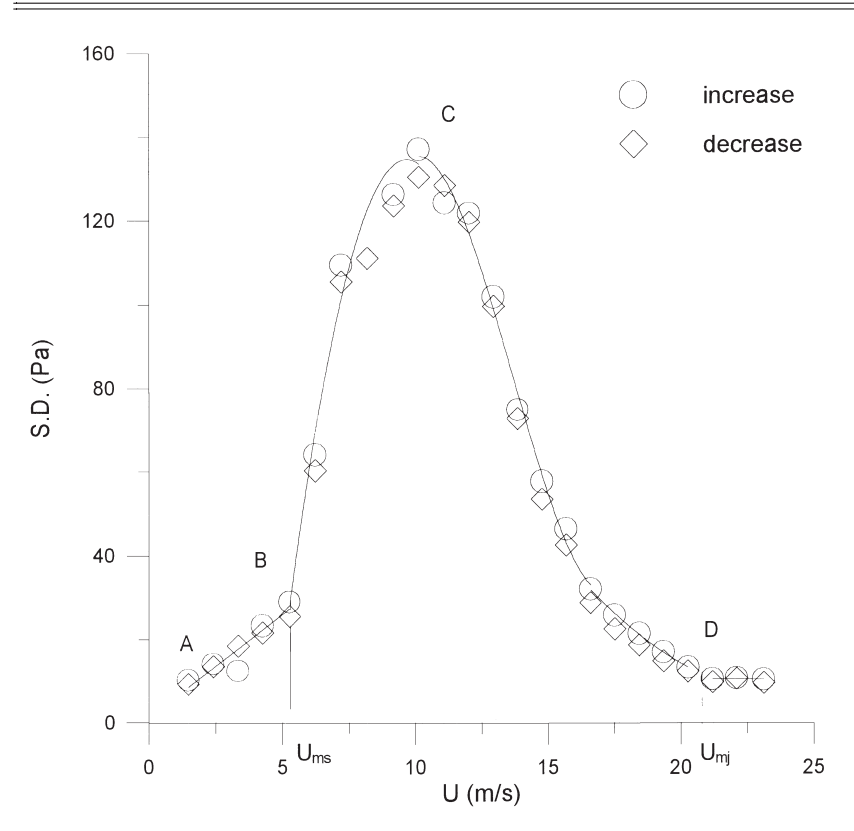

Figure 2. S. D. vs. superficial gas velocity for glass beads in jet spouted beds. $\left(H_{v}=4 \mathrm{~cm}, d_{p}=3 \mathrm{~mm}, \gamma=40^{\circ}\right)$.
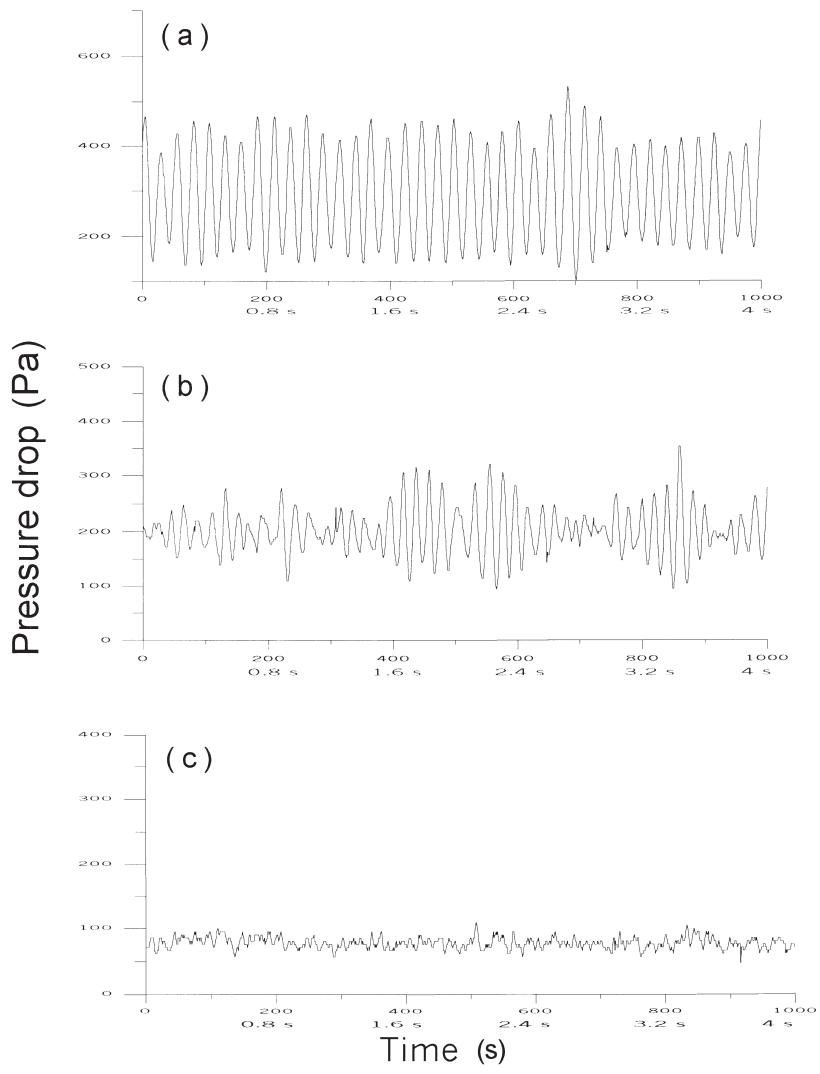

Figure 3. Pressure drop vs. time and sampled points for glass beads in (a) spouted bed $(U=4.3 \mathrm{~m} / \mathrm{s})$, (b) transition state $(U=12 \mathrm{~m} / \mathrm{s})$ and (c) jet spouted bed $(U=19.4 \mathrm{~m} / \mathrm{s}) .\left(H_{o}=3 \mathrm{~cm}, d_{p}=3 \mathrm{~mm}, \gamma=40^{\circ}\right)$.

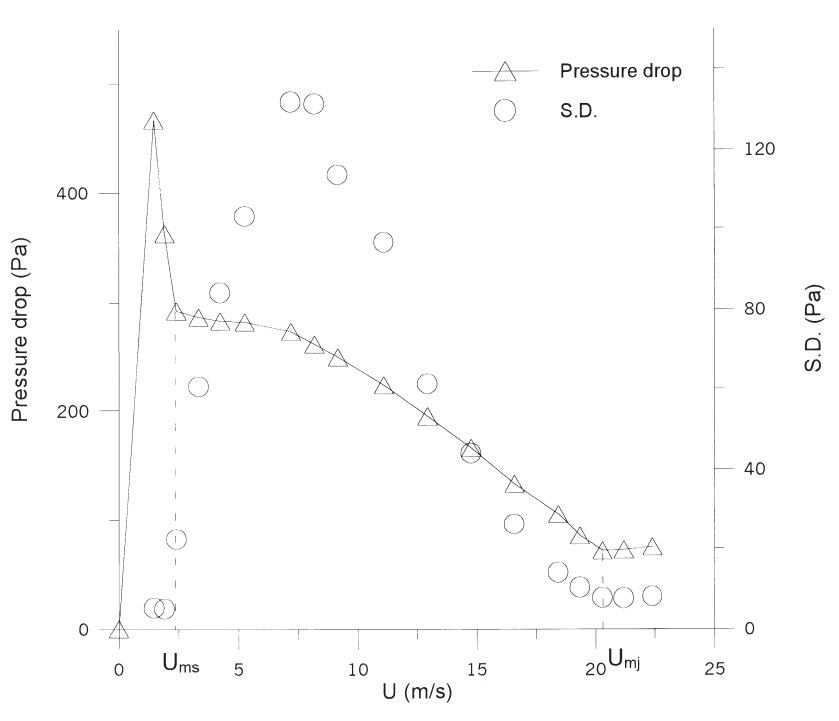

Figure 4. Pressure drop and S. D. vs. superficial gas velocity for rice particles in jet spouted beds. $\left(H_{o}=4 \mathrm{~cm}, d_{p}=3.1 \mathrm{~mm}, \gamma=40^{\circ}\right)$.

\section{Experimental}

Laboratory scale experiments were performed in Plexiglas beds with a conical base. The cone angles of the beds are 30, 36 and 40 degrees respectively. The geometry and the dimensions of the beds used in the experiments are shown in Figure 1. A pressure probe was located below the gas inlet; the other end of the pressure probe was connected to a pressure transducer. The obtained pressure fluctuation signals were sent to the data acquisition system for analysis, storage for future use. Air at ambient temperature from a blower flows through a buffer tank and flow meter and then through the bed. The solids used correspond to the Geldart group D particles (Geldart, 1973), and their properties are shown in Table 1. The inlet pipe was made according to the suggestion of Olazar et al. (1992) in order to avoid the pressure drop increase and to avoid the instability. There is a small region of cylindrical section at the gas inlet. This may mean a difference with respect to conical geometry, but during the experiments, no solid accumulation at the inlet was observed. Also, no effect on stability was found.

\section{Results and Discussion}

\section{Standard Deviation of Pressure Fluctuations}

Figure 2 shows the relationship between the standard deviation (S.D.) of pressure fluctuations vs. superficial gas velocity. At the beginning, the bed is in the state of fixed bed, particles are motionless. As the superficial gas velocity increases, the pressure drop increases. After the superficial gas velocity is high enough, the resulting high velocity jet causes a stream of particles to rise rapidly in a hollowed central core within the bed of solids. These particles, after reaching somewhat above the peripheral bed level, rain back into the annular region between the hollowed core and the column wall where they slowly travel downward and, to some extent, inward as a loosely packed bed. As the gas travels upwards, it flares out into the annulus. The bed consisted of three regions, dilute phase central core (spout) with upward moving solids 


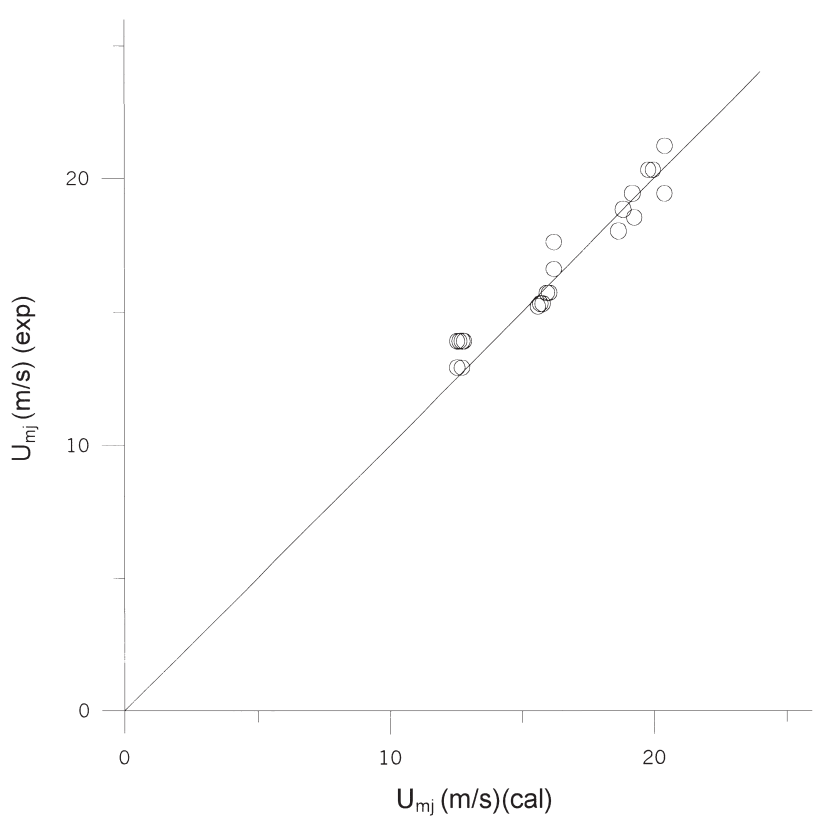

Figure 5. Comparison of experimental results of $U_{m j}$ with the results calculated by using Equation (1).

The comparison of experimental data and the calculated results are shown in Figure 5. It was found that they were in good agreement.

\section{Conclusion}

The spherical shape and non-spherical rice particles were used in a conical spouted bed with $30^{\circ}, 36^{\circ}$ and $40^{\circ}$ cone angles. The minimum jet spouted velocity could be easily found from the measurement of standard deviation of pressure fluctuations. The waveform of pressure time signals could be used to determine the different flow regimes of spouted bed, transition region and jet spouted bed. The minimum jet spouted velocity increased with the increase of particle size and static bed height.

\section{Nomenclature}

\footnotetext{
Ar Archimedes number $=g d_{p}{ }^{3} \rho_{f}\left(\rho_{s}-\rho_{f}\right) / \mu^{2}$

$D_{c} \quad$ diameter of the column, $(\mathrm{m})$

$D_{b} \quad$ top diameter of a static bed, $(\mathrm{m})$
}

$D_{i} \quad$ diameter of the contactor base, $(\mathrm{m})$

$D_{0} \quad$ diameter of the contactor inlet, $(\mathrm{m})$

$d_{p} \quad$ particle size, $(\mathrm{m})$

$H_{c} \quad$ height of the conical section, (m)

$H_{0} \quad$ static bed height, $(\mathrm{m})$

$\left(R e_{o}\right)_{m j} \quad$ Reynolds number at minimum jet spouting based on $D_{\mathrm{o}}$

S.D. $\quad$ standard deviation of pressure fluctuations, $(\mathrm{Pa})$

$U \quad$ superficial gas velocity based on $D_{0^{\prime}}(\mathrm{m} / \mathrm{s})$

$U_{m j} \quad$ minimum jet spouting velocity, $(\mathrm{m} / \mathrm{s})$

$U_{m s} \quad$ minimum spouting velocity, $(\mathrm{m} / \mathrm{s})$

\section{Greek Symbols}

$\gamma \quad$ cone angle, (degree)

$\mu \quad$ viscosity of fluid, (Pa.s)

$\rho_{f} \quad$ density of fluid, $\left(\mathrm{kg} / \mathrm{m}^{3}\right)$

$\rho_{s} \quad$ density of particles, $\left(\mathrm{kg} / \mathrm{m}^{3}\right)$

\section{References}

Chen, C. C. and C. L. Chen, "Experimental Study of Bed-to-Wall Heat Transfer in a Circulating Bed", Chem. Eng. Sci. 47, 1017-1025 (1992).

Geldart, D., "Types of Gas Fluidization, Powder Technol." 7, 285-292 (1973).

Leu, L.P. and C.Y. Teng, "Heat Transfer in Jet Spouted Beds", $4^{\text {th }}$ Kyushu/Taipei Chemical Engineering Conference, P-23, Miyazaki University, Miyazaki, Japan (2000).

Markowski, A. and W. Kaminski, "Hydrodynamic Characteristics of JetSpouted Beds", Can. J. Chem. Eng." 61, 377-381 (1983).

Mathur, K. B. and N. Epstein, "Spouted Beds", Academic Press, New York, NY (1974), pp.14-46.

Mathur, K. B. and P. E. Gishler, "A Study of the Application of the Spouted Bed Technique to Wheat Drying", J. Appl. Chem., London, 5, 624-631 (1955).

Olazar, M., M. J. San Jose, A. T. Aguayo, J. M. Arandes and J. Bilbao, "Stable Operation Conditions for Gas-Solid Contact Regimes in Conical Spouted Beds", Ind. Eng. Chem. Res. 31, 1784-1792 (1992).

San Jose, M. J., M. Olazar, A. T. Aguayo, J. M. Arandes and J. Bilbao, "Hydrodynamic Correlations of Conical Jet Spouted Beds", in "Fluidization VII", O. E. Potter and D. J. Nicklin, Eds., Engineering Foundation, New York, NY (1992), pp. 381-388.
Manuscript received July 14, 2003; revised manuscript received April 29, 2004; accepted for publication July 29, 2004. 